\title{
Enhanced oral bioavailability of docetaxel by lecithin nanoparticles: preparation, in vitro, and in vivo evaluation
}

This article was published in the following Dove Press journal:

International Journal of Nanomedicine

6 July 2012

Number of times this article has been viewed

\author{
Kaili $\mathrm{Hu}^{\prime}$ \\ Shan $\mathrm{CaO}^{1,2}$ \\ Fuqiang $\mathrm{Hu}^{3}$ \\ Jianfang Feng' \\ 'Murad Research Center for \\ Modernized Chinese Medicine, \\ Shanghai University of Traditional \\ Chinese Medicine, Shanghai, \\ 2Pharmacy Department, Baoshan \\ Central Hospital, Shanghai, ${ }^{3}$ School \\ of Pharmacy, Zhejiang University, \\ Hangzhou, China
}

\begin{abstract}
The aim of this research work was to investigate the potential of lecithin nanoparticles (LNs) in improving the oral bioavailability of docetaxel. Docetaxel-loaded LNs (DTXLNs) were prepared from oil-in-water emulsions and characterized in terms of morphology, size, zeta potential, and encapsulation efficiency. The in vitro release of docetaxel from the nanoparticles was studied by using dialysis bag method. Caco-2 cell monolayer was used for the in vitro permeation study of DTX-LNs. Bioavailability studies were conducted in rats and different pharmacokinetic parameters were evaluated after oral administration of DTX-LNs. The results showed that DTX-LNs had a mean diameter of $360 \pm 8 \mathrm{~nm}$ and exhibited spherical shape with smooth surface under transmission electron microscopy. The DTX-LNs showed a sustained-release profile, with about $80 \%$ of docetaxel released within 72 hours. The apical to basolateral transport of docetaxel across the Caco- 2 cell monolayer from the DTX-LNs was 2.14 times compared to that of the docetaxel solution $\left(0.15 \times 10^{-5} \pm 0.016 \times 10^{-5} \mathrm{~cm} / \mathrm{second}\right.$ versus $\left.0.07 \times 10^{-5} \pm 0.003 \times 10^{-5} \mathrm{~cm} / \mathrm{second}\right)$. The oral bioavailability of the DTX-LNs was 3.65 times that of docetaxel solution ( $8.75 \%$ versus $2.40 \%$ ). These results indicate that DTX-LNs were valuable as an oral drug delivery system to enhance the absorption of docetaxel.
\end{abstract}

Keywords: lecithin nanoparticles, oral delivery, docetaxel, bioavailability

\section{Introduction}

Docetaxel, a second-generation taxoid which was synthesized from 10-deacetylbaccatin III (a noncytotoxic constituent of European yew needles), has been considered one of the most important antitumor drugs in clinical use for cancer. ${ }^{1}$ It was registered for anthracycline-resistant breast cancer, second-line treatment of nonsmall cell lung cancer, and first-line treatment of advanced nonsmall cell lung cancer in combination with cisplatin. However, due to its poor solubility in water, the development of suitable formulations for anticancer chemotherapy was greatly hindered. The marketed Taxotere ${ }^{\circledR}$ for intravenous infusion contained Tween ${ }^{\circledR} 80$ (polysorbate 80 ) and ethanol to enhance the solubility of docetaxel. ${ }^{2}$ The Tween 80 with high viscosity caused hemolysis, so patients were often subjected to hypersensitivity after administration. ${ }^{3}$ Due to this adverse effect, premedication was frequently required. To avoid these disadvantages, enhance patient's convenience, and facilitate the use of more chronic treatment regimens, many studies have been directed towards developing new oral formulations of docetaxel. ${ }^{4-6}$

Oral delivery was the preferred route for systemic delivery of drugs because it afforded easy handling, high patient compliance, less stringent production conditions, and lower costs. ${ }^{7}$ The major problem for oral delivery of docetaxel is its 
low bioavailability, which in part is caused by the excretion effect of P-glycoprotein. Recently, nanoscale drug delivery systems have offered new promise for the rational delivery of chemotherapeutic drugs in the treatment of cancer. It could improve pharmacokinetic properties, enable controlled and sustained drug release, and, more importantly, lower systemic toxicity. ${ }^{8}$ Maincent et al were the first to demonstrate that nanoparticles could improve the oral bioavailability of drugs in $1984 .{ }^{9,10}$ After oral administration, the nanoparticles could control the release of drugs, reduce gastrointestinal mucosal irritation, and ensure their stability in the gastrointestinal tract. ${ }^{11}$ Lecithin nanoparticles (LNs) were reported to be able to increase antitumor effects of docetaxel after intravenous injection with good biocompatibility. ${ }^{12}$ Lecithin is a combination of acetone-insoluble phosphatides that combines with various amounts of other substances such as triglycerides and fatty acids. It is a component of cell membranes and is consumed as a normal part of the diet. Therefore, it has been used in a wide variety of pharmaceutical applications as a dispersing, emulsifying, and stabilizing agent and has been included in intramuscular and intravenous injectables, parenteral nutrition formulations, and topical products. ${ }^{13}$

The aim of this study was to investigate the potential of LNs in improving the oral bioavailability of docetaxel. Docetaxel-loaded LNs (DTX-LNs) were prepared from oilin-water emulsions. The formulations were characterized in encapsulation efficiency, size, zeta potential, and in vitro release. The permeation of docetaxel through the Caco-2 cell monolayer and bioavailability of docetaxel after oral administration of DTX-LNs to rats were compared to both docetaxel solution and docetaxel solution with cyclosporine A (CsA).

\section{Materials and methods \\ Materials}

Docetaxel was purchased from Shanghai Techwell Biopharmaceutical Co, Ltd (Shanghai, China). Lecithin (Lipoid S 100) was obtained from Lipoid $\mathrm{GmbH}$ (Ludwigshafen, Germany). Docetaxel injection was from Hengrui Pharmaceutical Machinery Co, Ltd (Zhanjiagang, China). Cell counting kit-8 was from Dojindo Laboratories (Kumamoto, Japan). Cellulose dialysis tubes (molecular weight $14 \mathrm{kDa}$ ) were from Shanghai Bioscience Co, Ltd (Shanghai, China). Centrifugal filter units (Amicon ${ }^{\circledR}$ Ultra molecular weight $30 \mathrm{kDa}$ ) were from Millipore Corporation (Billerica, MA). Dulbecco's modified Eagle medium, fetal bovine serum, nonessential amino acid solution, $100 \mathrm{U} / \mathrm{mL}$ penicillin, and $100 \mu \mathrm{g} / \mathrm{mL}$ of streptomycin were from Invitrogen Life Technologies (Carlsbad, CA). Corning ${ }^{\circledR}$ Transwell $^{\circledR}$-COL inserts (Millicell ${ }^{\circledR} 0.4 \mu \mathrm{m}$ polyvinylpyrrolidone-free polycarbonate membrane) and the 24-well Transwell $\operatorname{Costar}^{\circledR}$ culture plate were from SigmaAldrich Corporation (St Louis, MO). All other chemicals and solvents were of analytical reagent grade.

\section{Animals and cell lines}

Male Sprague Dawley rats of 200-250 g weight were from Shanghai Super B\&K Laboratory Animal Corporation Ltd (Shanghai, China) and maintained at $22^{\circ} \mathrm{C} \pm 2^{\circ} \mathrm{C}$ on a 12 -hour light-dark cycle with access to food and water ad libitum. The animals used for the experiment were treated according to the protocols evaluated and approved by the ethical committee of Shanghai University of Traditional Chinese Medicine (Shanghai, China). Caco-2 cells were a kind gift from Associate Professor Jianxin Wang (School of Pharmacy, Fudan University, Shanghai, China). The cells were cultured in Dulbecco's modified Eagle medium containing 10\% fetal bovine serum, $1 \%$ nonessential amino acid solution, $100 \mathrm{U} / \mathrm{mL}$ penicillin, and $100 \mu \mathrm{g} / \mathrm{mL}$ of streptomycin at $37^{\circ} \mathrm{C}$ in an atmosphere of $5 \%$ carbon dioxide.

\section{Preparation of DTX-LNs}

DTX-LNs were prepared from oil-in-water emulsions with lecithin as the oil phase and Tween 20 as the surfactant. ${ }^{12}$ Briefly, $40 \mathrm{mg}$ lecithin was added into $1 \mathrm{~mL}$ chloroform containing $2 \mathrm{mg}$ docetaxel. After the chloroform was evaporated by stirring, $10 \mathrm{~mL}$ deionized warm water (filtered through $0.2 \mu \mathrm{m}$ membrane) was added and the solution was heated to $65^{\circ} \mathrm{C}$ with stirring until a milky dispersion was formed. Then, Tween 20 was added dropwise to a final concentration of $1 \%$ weight/volume (w/v). The system was stirred until it became less opaque but not clear, and then it was cooled down to room temperature. Free docetaxel was separated from the DTX-LNs by ultracentrifugation at $8000 \mathrm{rpm}$ for 1 hour at $4^{\circ} \mathrm{C}$ (5810 R; Eppendorf, Hamburg, Germany) using a centrifugal filter unit (Amicon Ultra; Millipore).

\section{Physicochemical characterization of DTX-LNs}

The surface morphology of DTX-LNs was observed under transmission electron microscope (CM-200 FEG; Philips, Eindhoven, Netherlands) after negative staining with phosphotungstic acid solution $(2 \%, \mathrm{w} / \mathrm{v})$.

The size and zeta potential of the DTX-LNs were measured by the light scattering method. The analyses 
were performed with a helium-neon laser $(632.8 \mathrm{~nm})$ at a scattering angle of 90 degrees at $25^{\circ} \mathrm{C}$ using a Nicomp ${ }^{\mathrm{TM}} 380$ ZLS (Particle Sizing Systems, Port Richey, FL). The samples of nanoparticles were diluted to the appropriate concentration using deionized water before measurement.

\section{Drug encapsulation efficiency and drug loading}

The drug content of DTX-LNs was detected by highperformance liquid chromatography (HPLC) after being dissolved in an appropriate volume of methanol. HPLC analysis was performed using a Hypersil ${ }^{\mathrm{TM}}$ ODS-2 column (4.6 mm $\times 250 \mathrm{~mm}, 5-\mu \mathrm{m}$ particle size; Elite Analytical Instruments Co, Ltd, Dalian China) on a Shimadzu ${ }^{\circledR}$ HPLC system (LC-20A; Shimadzu Corporation, Tokyo, Japan) with an ultraviolet detector at room temperature. The wavelength of the ultraviolet detector was set at $230 \mathrm{~nm}$. Acetonitrile and water (55:45 volume/volume [v/v]) was used as the mobile phase at a flow rate of $1 \mathrm{~mL} /$ minute. The accurate weight of nanoparticles was detected after lyophilization. The drug entrapment efficiency and drug loading was calculated by the following equations:

$$
\begin{gathered}
\text { Entrapment efficiency }(\%)=\frac{W_{D T X}}{W_{T o t a l}} \\
\text { Drug loading }(\%)=\frac{W_{D T X}}{W_{D T X-L N s}}
\end{gathered}
$$

$W_{D T X}$ represents the amount of docetaxel loaded in the DTXLNs, $W_{\text {Total }}$ represents the total docetaxel amount added during preparation of the DTX-LNs, and $W_{D T X-L N S}$ represents the weight of the DTX-LNs.

\section{In vitro release studies}

The in vitro release of docetaxel from the nanoparticles was determined by the dialysis bag method. The DTX-LNs were dispersed in $1 \mathrm{~mL}$ of phosphate buffered saline (PBS; $\mathrm{pH}$ 7.4; final docetaxel concentration $100 \mu \mathrm{g} / \mathrm{mL}$ ) and placed into cellulose ester dialysis bags. The dialysis bags were immersed in $100 \mathrm{~mL}$ release medium ( $\mathrm{pH} 7.4 \mathrm{PBS}$ containing $0.5 \% \mathrm{w} / \mathrm{v}$ sodium dodecyl sulfate) or release medium with $5 \mathrm{~mL}$ plasma (to investigate the effect of plasma protein on the release of docetaxel from the nanoparticles) at $37^{\circ} \mathrm{C}$ with horizontal shaking at $50 \mathrm{rpm}$. Docetaxel solution $(100 \mu \mathrm{g} / \mathrm{mL}$; dissolved in PBS containing $100 \mu \mathrm{g} / \mathrm{mL}$ Tween 80 and $6.5 \%$ ethanol) was also subjected to the release study to make sure that the diffusion of the docetaxel molecules across the membrane was not limited by the dialysis bag. At predetermined time points, $1 \mathrm{~mL}$ dissolution media was withdrawn and the samples were properly diluted by methanol and centrifuged at 10,000 rpm for 5 minutes. The supernatant $(10 \mu \mathrm{L})$ was then directly injected into the HPLC system and analyzed for the released docetaxel. The release profiles were plotted and fitted using different in vitro release models.

\section{Permeation of docetaxel through the Caco-2 cell monolayer}

Caco-2 cell monolayer was used for the in vitro permeation study of DTX-LNs. Caco-2 cells were grown in Dulbecco's modified Eagle medium containing 10\% fetal bovine serum, $1 \%$ nonessential amino acid solution, $100 \mathrm{U} / \mathrm{mL}$ penicillin, and $0.1 \mathrm{mg} / \mathrm{mL}$ streptomycin at $37^{\circ} \mathrm{C}$ in an atmosphere of $5 \%$ carbon dioxide. Before the experiment, the cells were seeded onto the apical side of collagen-coated Transwell-COL inserts in 24-well Transwell culture plate at a concentration of $1.2-1.5 \times 10^{5}$ cells/well. Culture medium was added to the apical $(0.4 \mathrm{~mL})$ and basolateral $(0.6 \mathrm{~mL})$ side, and was replaced every other day for the first week and daily thereafter. Cells were incubated for 21-25 days until the transepithelial electrical resistance (EVOM voltohmmeter; World Precision Instruments Inc, Sarasota, FL) increased to $600 \Omega / \mathrm{cm}^{2}$.

Before the permeation study, the monolayer was washed three times with preheated $37^{\circ} \mathrm{C}$ transport media, which was Hanks' balanced salt solution containing $5 \mathrm{mM}$ D-glucose and $5 \mathrm{mM}$ 4-(2-hydroxyethyl)-1-piperazineethanesulfonic acid ( $\mathrm{pH}$ 7.4). For the apical to basolateral (A to B) transport study, $0.4 \mathrm{~mL}$ DTX-LN suspension or docetaxel solution (containing $10 \mu \mathrm{M} \mathrm{CsA}$ and $0.1 \% \mathrm{v} / \mathrm{v}$ dimethyl sulfoxide) with a docetaxel concentration of $40 \mu \mathrm{g} / \mathrm{mL}$ were added to the apical side, while $0.4 \mathrm{~mL}$ of docetaxel solution $(40 \mu \mathrm{g} / \mathrm{mL})$ in transport medium containing $0.1 \% \mathrm{v} / \mathrm{v}$ dimethyl sulfoxide was added as the control; $0.6 \mathrm{~mL}$ transport medium was added in the basolateral side. At predetermined time intervals, $0.3 \mathrm{~mL}$ of medium in basolateral side was withdrawn and replaced with fresh medium. For the basolateral to apical (B to A) transport study, $0.6 \mathrm{~mL}$ DTX-LN suspension or docetaxel solution (containing $10 \mu \mathrm{M} \mathrm{CsA}$ and $0.1 \% \mathrm{v} / \mathrm{v}$ dimethyl sulfoxide) with a docetaxel concentration of $40 \mu \mathrm{g} / \mathrm{mL}$ was added to the basolateral side, while $0.6 \mathrm{~mL}$ of docetaxel solution $(40 \mu \mathrm{g} / \mathrm{mL})$ in transport medium containing $0.1 \% \mathrm{v} / \mathrm{v}$ dimethyl sulfoxide was added as the control; $0.4 \mathrm{~mL}$ transport medium was added in the apical side. At predetermined time intervals, $0.3 \mathrm{~mL}$ medium was taken from the apical side and replaced with fresh medium. The concentration of docetaxel 
in the medium was determined by a validated HPLC method, and the cumulative permeated amount of docetaxel was plotted as a function of time. The apparent permeability coefficient was determined from the linear slope of the plot using the following equation:

$$
\mathrm{P}_{\mathrm{app}}=\frac{d Q}{d \mathrm{t}} \frac{1}{\mathrm{~A} \cdot \mathrm{C}_{0}}
$$

$\mathrm{P}_{\text {app }}$ represents the apparent permeability coefficient (cm/second), $d Q / d t$ represents the steady state flux, A indicates the surface area of membrane $\left(\mathrm{cm}^{2}\right)$, and $\mathrm{C}_{0}$ was the initial concentration of docetaxel in the apical (for A to B transport) or basolateral (for B to A transport) side.

\section{Pharmacokinetic studies}

Before the experiment, the rats were fasted overnight with free access to water and randomly divided into four groups. The diluted docetaxel injection ( $2 \mathrm{mg} / \mathrm{mL}$ with $20 \% \mathrm{v} / \mathrm{v}$ ethanol) was administered intravenously at doses of $20 \mathrm{mg} / \mathrm{kg}$. The DTX-LN suspension, docetaxel solution, and docetaxel with CsA solution (with $2.25 \mathrm{mg} / \mathrm{mL}$ CsA, 25\% w/v Tween 80, and $9.75 \% \mathrm{v} / \mathrm{v}$ ethanol) were diluted with physiological saline to a docetaxel concentration of $3 \mathrm{mg} / \mathrm{mL}$ and administered orally at a dose of $20 \mathrm{mg} / \mathrm{kg}$. Whole blood samples were collected by retro-orbital puncture into heparinized tubes at $0.5,1,2$, 4,8 , and 12 hours following oral administration and at 2 , 5 , and 15 minutes and $0.5,1,2,4$, and 8 hours following intravenous administration. The plasma samples obtained were immediately centrifuged at 10,000 rpm for 5 minutes, and $100 \mu \mathrm{L}$ of the supernatant was transferred to new glass tubes and stored at $-20^{\circ} \mathrm{C}$.

The plasma samples were extracted twice with diethyl ether before HPLC analysis. Briefly, $100 \mu \mathrm{L}$ plasma was mixed with $10 \mu \mathrm{L}$ paclitaxel $(2 \mu \mathrm{g} / \mathrm{mL})$ as the internal standard. The samples were then extracted with $1 \mathrm{~mL}$ diethyl ether by vigorous mixing for 5 minutes. The organic phase was collected after centrifugation at 10,000 rpm for 5 minutes, combined after repeating the above extraction procedure, and then dried under nitrogen gas stream at $40^{\circ} \mathrm{C}$. The residue was then dissolved with $200 \mu \mathrm{L}$ acetonitrile and mixed for 5 minutes. The solution was centrifuged for 5 minutes at $10,000 \mathrm{rpm}$, and $10 \mu \mathrm{L}$ of the supernatant was injected into the HPLC system.

The pharmacokinetic parameters of each formulation were calculated by the noncompartmental method. The area under the curve and the mean residence time were determined by standard methods applying the linear trapezoidal rule. The maximum plasma concentration and time taken to reach the maximum plasma concentration were determined by a visual inspection of the experimental data. The absolute bioavailability of docetaxel after oral administration compared to the intravenous administration was calculated as follows:

$$
\mathrm{F}(\%)=\frac{\mathrm{AUC}_{\text {oral }}}{\mathrm{AUC}_{\mathrm{IV}}} \times \frac{\mathrm{IV} \text { dose }}{\text { Oral dose }} \times 100
$$

F represents the absolute bioavailability, AUC represents the area under the curve, and IV stands for intravenous.

\section{Statistical analysis}

All mean values were presented with their standard deviations. A two-tailed unpaired Student's $t$-test was performed at $P<0.05$.

\section{Results and discussion Characterization of DTX-LNs}

Transmission electron microscope imaging results showed that the DTX-LNs had spherical and uniform shapes (Figure 1). Light scattering analysis indicated the size of the nanoparticles was $360 \pm 8 \mathrm{~nm}$ (polydispersity index: $0.198 \pm 0.04)$ with a zeta potential of $-14.2 \pm 0.25 \mathrm{mV}$. After suspension in $0.01 \mathrm{M}$ PBS, DTX-LN particle size was stable for at least 72 hours. It was observed that the particle size of nanoparticles affected the cellular uptake of the nanoparticles. The permeability of the particles through

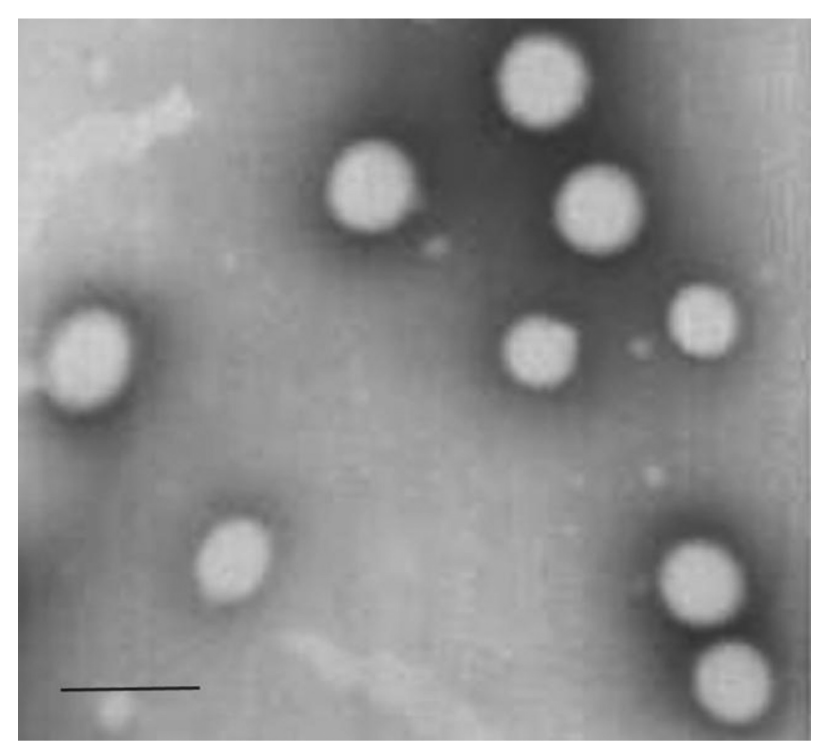

Figure I Transmission electron microscopic photograph of docetaxel-loaded lecithin nanoparticles.

Note: The scale bar is $500 \mathrm{~nm}$. 
the intestinal mucosa decreases with increasing the particle size, reaching a cutoff at $500 \mathrm{~nm} .{ }^{14}$ The prepared DTX-LNs were $300-400 \mathrm{~nm}$ in diameter, which is in the size range favoring the intestinal uptake of the nanoparticles. ${ }^{15}$ The calculated entrapment efficiency and drug loading of the DTXLNs was $94.6 \% \pm 1.8 \%$ and $1.13 \% \pm 0.02 \%$, respectively. In preliminary experiments, attempts were made to maximize drug loading of the DTX-LNs by adjusting the amount of docetaxel added in preparation. The results showed that $2 \mathrm{mg}$ docetaxel in the formulation resulted in the best entrapment efficiency and drug loading. Further increasing the docetaxel amount did not improve drug loading, which was consistent with public research showing that after achieving the best entrapment efficiency of lecithin nanoparticles, the increase of docetaxel content would only enhance the docetaxel content in the micelle fractions. ${ }^{12}$ These results demonstrate that the prepared lecithin nanoparticles had a sound particle size and relative high encapsulation efficiency which was favorable for oral delivery.

\section{In vitro release of docetaxel from DTX-LNs}

In the in vitro release study, dynamic dialysis was chosen for separation of free docetaxel from the DTX-LNs. To provide a sink condition, $0.5 \% \mathrm{w} / \mathrm{v}$ sodium dodecyl sulfate was added to the release medium. The DTX-LNs showed biphasic release profiles in 0.01 M PBS and plasma, with a slightly slower release in the plasma (Figure 2). Within 24 hours, $64.4 \%$ and $59.4 \%$ of docetaxel was released in 0.01 M PBS and plasma, respectively. The first 24 hours was a fast-release phase, which could be related to the release of the drug encapsulated near the particle surface. After this phase, a constant slow release of $60 \%-80 \%$ of the loaded docetaxel was observed, showing a typical sustained and prolonged drug release which may be dependent on drug diffusion and matrix erosion mechanisms. ${ }^{16}$ The result was similar to those of many studies reporting that drug-loaded lipid nanoparticles provided a controlled-release pattern. ${ }^{12,17}$ The docetaxel solution released about $85 \%$ in the first 8 hours and reached a total release after 72 hours, which demonstrated that the diffusion of docetaxel across the semipermeable dialysis membrane was not a rate-limiting process. The release profiles in both medium best fitted into the Weibull equation (Table 1). The sustained-release property of DTXLNs might enhance the permeation of docetaxel in vitro as well as the absorption of docetaxel in vivo.

\section{Permeation through the Caco-2 cell monolayer}

The Caco- 2 cell monolayer is a well-characterized, enterocytelike, easily maintained human colon adenocarcinoma cell line that was prevalently used for the assessment of drug permeability, transport, and metabolism. ${ }^{18}$ In preliminary studies, a less than $90 \%$ viability of Caco-2 cells was found when docetaxel concentration was above $50 \mu \mathrm{g} / \mathrm{mL}$ and when each group was contacted with the cells for more than 4 hours by cell counting kit-8 assay (data not shown). Thus, in the following experiments, 4-hour permeation studies were conducted at the highest docetaxel concentration $(40 \mu \mathrm{g} / \mathrm{mL})$. The A to B and B to A transport of docetaxel through the Caco-2 cell monolayer in each group are shown in Figure 3. The apparent permeability values of docetaxel were compared and the results are shown in Table 2. Docetaxel was reported as a P-glycoprotein substrate whose oral absorption is in part affected by P-glycoprotein efflux. ${ }^{19}$ The permeability coefficient of the DTX-LNs was higher than that of the

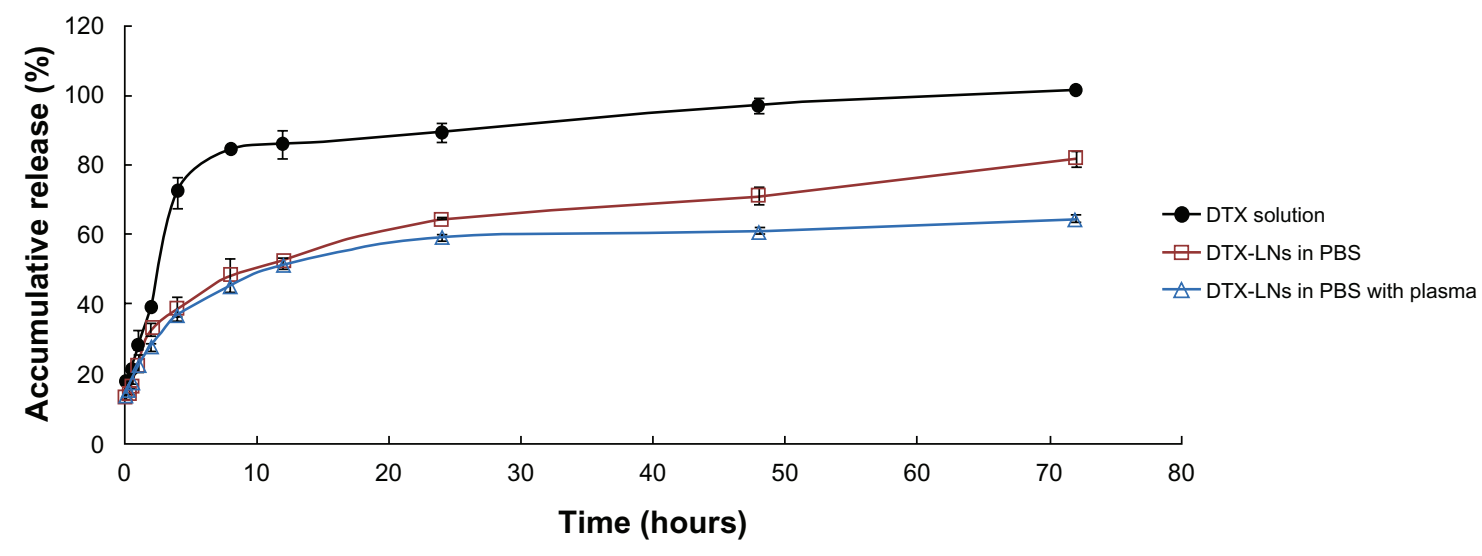

Figure 2 The in vitro release of the docetaxel-loaded lecithin nanoparticles in 0.01 M phosphate buffered saline with and without plasma. Note: The values represent mean \pm standard deviation $(n=3)$.

Abbreviations: DTX, docetaxel; DTX-LNs, docetaxel-loaded lecithin nanoparticles; PBS, phosphate buffered saline. 
Table I In vitro release kinetics of docetaxel-loaded lecithin nanoparticles in $0.01 \mathrm{M}$ phosphate buffered saline and plasma

\begin{tabular}{lll}
\hline Release kinetics & $\mathbf{r}^{2}$ & \\
\cline { 2 - 3 } & PBS & Plasma \\
\hline Zero order & 0.7690 & 0.6559 \\
First order & 0.9147 & 0.7381 \\
Higuchi & 0.9377 & 0.8690 \\
Ritger-Peppas & 0.9778 & 0.9732 \\
Weibull & 0.9790 & 0.9762 \\
\hline
\end{tabular}

Abbreviations: PBS, phosphate buffered saline; $r^{2}$, correlation coefficient.

docetaxel solutions or docetaxel with CsA solutions in the A to B transport. In particular, the apparent permeability value of docetaxel from DTX-LNs was 2.14 times higher than that from docetaxel solutions $\left(0.15 \times 10^{-5} \pm 0.016 \times 10^{-5} \mathrm{~cm} / \mathrm{second}\right.$ versus $\left.0.07 \times 10^{-5} \pm 0.003 \times 10^{-5} \mathrm{~cm} / \mathrm{second}\right)$. The $\mathrm{B}$ to $\mathrm{A}$ permeability coefficient of the docetaxel solution was higher than that of the $\mathrm{A}$ to $\mathrm{B}$ value indicating that docetaxel is a substrate of P-glycoprotein. After the addition of CsA, the B to A apparent permeability values of docetaxel slightly decreased, which suggests a certain effect of P-glycoprotein suppression. In the DTX-LN group, the apparent permeability value of docetaxel from $\mathrm{A}$ to $\mathrm{B}$ was higher than that of $\mathrm{B}$ to $\mathrm{A}$,
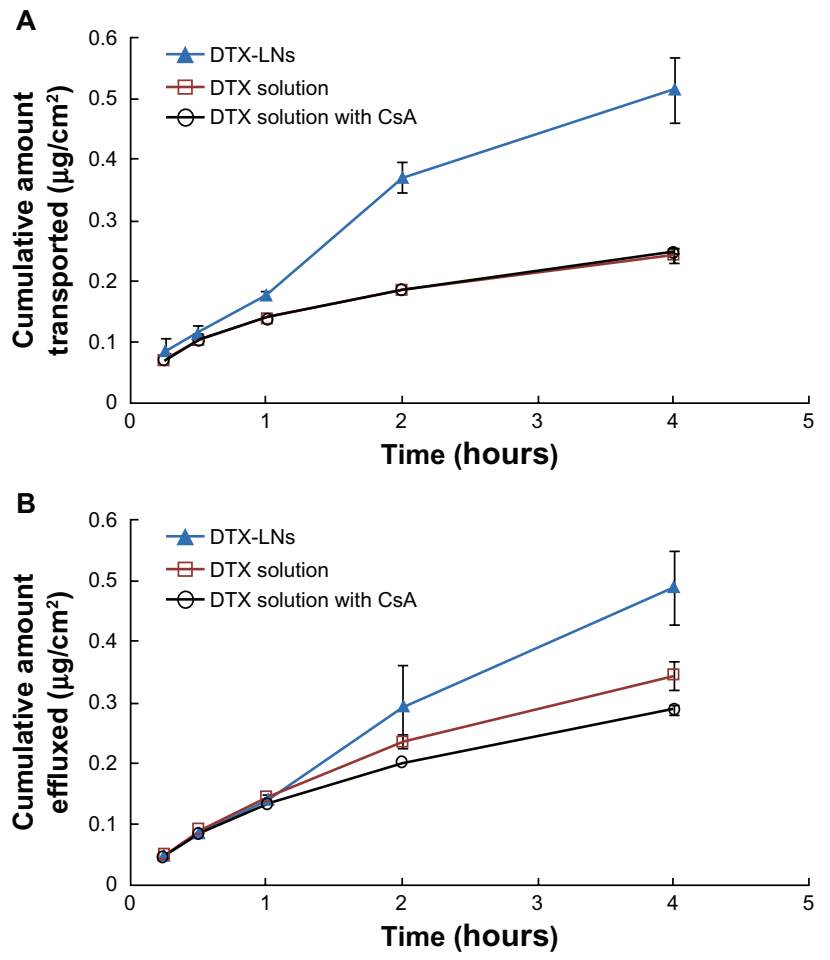

Figure 3 (A) Apical to basolateral and (B) basolateral to apical transport profiles of docetaxel-loaded lecithin nanoparticles, docetaxel solution, and docetaxel solution with cyclosporine A across the Caco-2 cell monolayer at $37^{\circ} \mathrm{C}$.

Note: The values represent mean \pm standard deviation $(n=4)$.

Abbreviations: CsA, cyclosporine A; DTX, docetaxel; DTX-LNs, docetaxel-loaded lecithin nanoparticles.
Table 2 The apparent permeability of docetaxel across the Caco-2 cell monolayer from each group

\begin{tabular}{lll}
\hline Group & \multicolumn{2}{l}{$\begin{array}{l}\text { Permeability coefficient } \\
\mathbf{P}_{\text {app }}\left(\times 10^{-5} \mathbf{c m} / \text { second }\right)\end{array}$} \\
\cline { 2 - 3 } & A to B & B to A \\
\hline DTX-LNs & $0.15 \pm 0.016^{*}$ & $0.14 \pm 0.017^{*}$ \\
DTX solution & $0.07 \pm 0.003$ & $0.10 \pm 0.007$ \\
DTX solution with CsA & $0.07 \pm 0.001$ & $0.08 \pm 0.002^{*}$
\end{tabular}

Notes: The values represent mean \pm standard deviation $(n=4) ; * P<0.05$ compared with docetaxel solution.

Abbreviations: $\mathrm{A}$ to $\mathrm{B}$, apical to basolateral transport; $\mathrm{B}$ to $\mathrm{A}$, basolateral to apical transport; CsA, cyclosporine A; DTX, docetaxel; DTX-LNs, docetaxel-loaded lecithin nanoparticles; $P_{\text {app }}$, apparent permeability.

although the B to A permeability coefficient also increased. The drug concentration inside the cells was the outcome of competition between the active export of drugs by P-glycoprotein and the passive permeation of drugs across the plasma membrane. Thus, increasing docetaxel permeation could occur either by inhibition of the efflux pumps or by acceleration of the drug permeation.

Nanoparticles with their submicron size and large specific surface area could favor their oral absorption. ${ }^{20,21}$ Enhanced uptake and prolonged retention of drug were also observed with nanoparticle-based formulations in P-glycoproteinoverexpressing cells. It was proved that the nanoparticle delivery system was able to bypass or inhibit P-glycoproteinmediated efflux and increase the internalization of drug into cells. ${ }^{22-24}$ In addition, Tween 20 was also able to modulate multidrug resistance by inhibition of P-glycoproteinmediated efflux. ${ }^{25}$ Therefore, the enhanced permeation of DTX-LNs may be the collective effects of both Tween 20 and nanoparticles. Nanoparticles are usually transported through the cell by one of these endocytotic mechanisms: pinocytosis, macropinocytosis, or clathrin-mediated endocytosis. ${ }^{23}$ Clathrin-coated vesicles can internalize particles smaller than $150 \mathrm{~nm}$, while during phagocytosis and macropinocytosis particles up to 3-4 $\mu \mathrm{m}$ can be internalized. ${ }^{26,27}$ According to the particle size of the DTX-LNs, the phagocytosis and macropinocytosis mechanism might be possible; however, the specific mechanism should be further studied.

\section{Pharmacokinetic studies}

The plasma concentration-time profiles of docetaxel after oral administration of docetaxel solution, DTX-LNs, and docetaxel solution with CsA to rats are shown in Figure 4 and the pharmacokinetic parameters are summarized in Table 3. The area under the curve of docetaxel in DTXLNs was 3.6-fold that of docetaxel solution $(P<0.01)$ and 3.1 -fold that of docetaxel solution with $\mathrm{CsA}(P<0.01)$. 


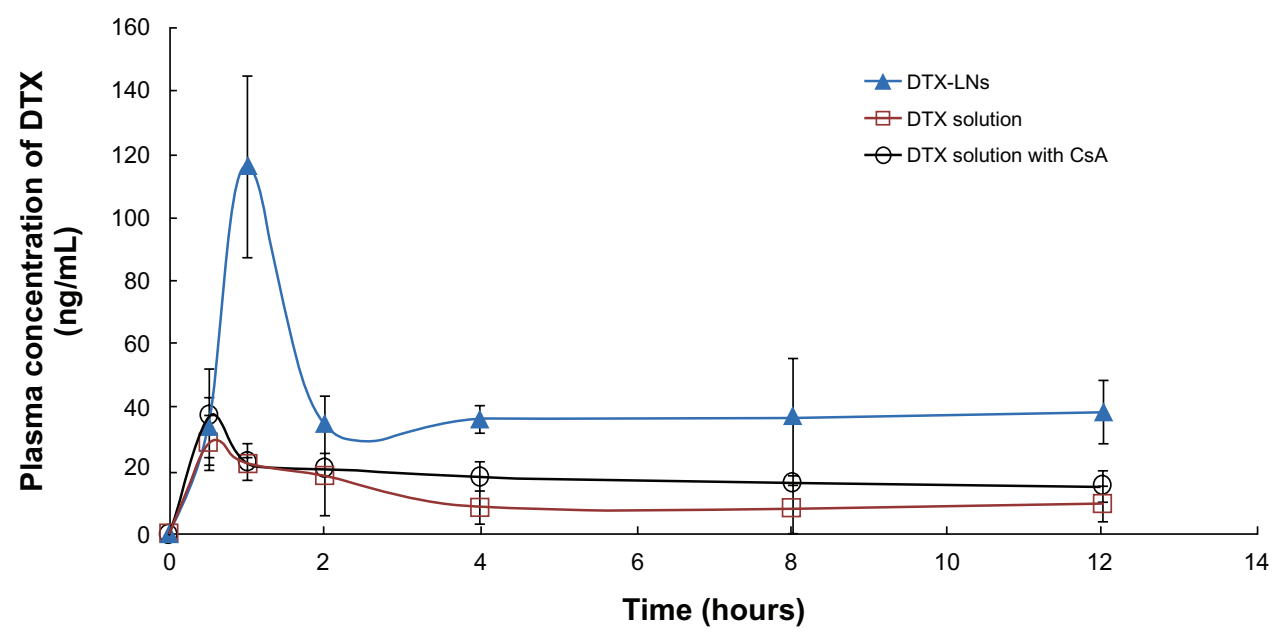

Figure 4 Plasma concentration-time profiles of docetaxel after oral administration of docetaxel solution, docetaxel-loaded lecithin nanoparticles, and docetaxel solution with cyclosporine A to rats at a docetaxel dose of $20 \mathrm{mg} / \mathrm{kg}$.

Note: The values reported were mean \pm standard deviation $(n=5)$.

Abbreviations: CsA, cyclosporine A; DTX, docetaxel; DTX-LNs, docetaxel-loaded lecithin nanoparticles.

The maximum plasma concentration of DTX-LNs was fourfold that of docetaxel solution $(P<0.01)$ and 3.1-fold that of docetaxel solution with $\mathrm{CsA}(P<0.05)$. The relatively slower time to maximum plasma concentration of DTX-LNs suggests a sustained-release profile of nanoparticles in vivo, which was consistent with the results of the in vitro release study. The increased area under the curve and maximum plasma concentration of DTX-LNs demonstrates an increased oral absorption, which correlates with the Caco-2 cell monolayer permeation results. Moreover, DTX-LNs showed a significantly higher absolute oral bioavailability $(8.75 \%)$ compared to that of orally administered docetaxel solution (2.40\%) and docetaxel solution with CsA (3.97\%).

The improved oral bioavailability of docetaxel in the nanoparticles might be attributed to the combination of the following effects. First, the uptake of DTX-LNs may occur in the gastrointestinal tract, the mechanisms of which include the diffusion of particles through mucus and accessibility to the enterocyte surface, epithelial interaction and cellular trafficking, and exocytosis and systemic dissemination. The particle size played a dominant role in the nanoparticle absorption rate. ${ }^{14}$ DTX-LN particle size under $500 \mathrm{~nm}$ allows efficient uptake in the intestine, particularly in the lymphoid sections, where they could bypass the liver first-pass metabolism. ${ }^{27,28}$ Second, the sustained-release property of the nanoparticles increased the circulation time of docetaxel, which prolonged the drug residence time in systematic circulation and resulted in better bioavailability. ${ }^{27}$ Third, the encapsulation of docetaxel into LNs might protect docetaxel from degradation and together with the effect of Tween 20 protect docetaxel from being recognized by the efflux transporters on the membrane of the small intestine. In addition, the lecithin materials might exert some effect on the permeation of docetaxel through

Table 3 Pharmacokinetic parameters after intravenous or oral administration of docetaxel formulations to rats

\begin{tabular}{|c|c|c|c|c|}
\hline & \multirow{2}{*}{$\begin{array}{l}\text { Intravenous } \\
\text { taxotere }^{\circledR}\end{array}$} & \multicolumn{3}{|l|}{ Oral } \\
\hline & & DTX-LNs & DTX solution & $\begin{array}{l}\text { DTX solution } \\
\text { with CsA }\end{array}$ \\
\hline Dose $(\mathrm{mg} / \mathrm{kg})$ & 20 & 20 & 20 & 20 \\
\hline $\mathrm{T}_{\max }(\mathrm{h})$ & 0.033 & I & 0.5 & 0.5 \\
\hline $\mathrm{C}_{\text {max }}(\mathrm{ng} / \mathrm{mL})$ & - & $116.19 \pm 28.58^{* *}$ & $28.99 \pm 8.84$ & $37.20 \pm 15.16^{\#}$ \\
\hline $\mathrm{AUC}(\mathrm{h} \cdot \mathrm{ng} / \mathrm{mL})$ & $5608.66 \pm 282.46$ & $490.74 \pm 37.28 * *$ & $134.83 \pm 21.46$ & $222.63 \pm 29.0 \mathrm{I}^{\#}$ \\
\hline $\mathrm{CL}_{\mathrm{t}}(\mathrm{L} / \mathrm{h} / \mathrm{kg})$ & $3.57 \pm 0.18$ & $40.95 \pm 3.16 * *$ & $151.55 \pm 25.45$ & $91.24 \pm 13.55^{\# \#}$ \\
\hline MRT (h) & $1.06 \pm 0.07$ & $5.60 \pm 0.34$ & $4.78 \pm 1.18$ & $5.44 \pm 0.56$ \\
\hline$F(\%)$ & - & 8.75 & 2.40 & 3.97 \\
\hline
\end{tabular}

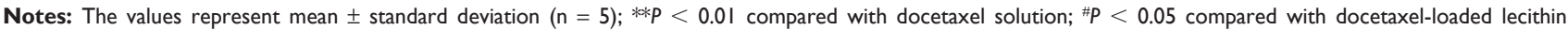
nanoparticles; ${ }^{\# P}<0.01$ compared with docetaxel-loaded lecithin nanoparticles.

Abbreviations: AUC, area under the curve; $\mathrm{CL}$, total clearance; $\mathrm{C}_{\text {mix }}$, maximum plasma concentration; CsA, cyclosporine A; DTX, docetaxel; DTX-LNs, docetaxel-loaded lecithin nanoparticles; $\mathrm{F}$, bioavailability; $h$, hours; $M R T$, mean retention time; $\mathrm{T}_{\max }$, time to maximum plasma concentration. 
the intestine membrane, improve the affinity between the nanoparticles and the intestinal membrane, and may also exhibit bioadhesion to the gastrointestinal tract wall. ${ }^{29,30}$ However, the specific mechanism will need to be elucidated by further studies.

\section{Conclusion}

In this paper, a novel oral delivery system of docetaxel (DTX-LNs) was prepared to improve the oral bioavailability of docetaxel. The prepared nanoparticles had a diameter of $360 \pm 8 \mathrm{~nm}$ with an encapsulation efficiency of $94.6 \% \pm 1.8 \%$. The in vitro release studies demonstrated the sustainedrelease properties of DTX-LNs. The Caco-2 monolayer transport study and pharmacokinetics study results suggest increased permeation of DTX-LNs in vitro and increased absorption in vivo compared with docetaxel solution. In addition, the absolute bioavailability of DTX-LNs was 3.65 times that of docetaxel solution. These results suggest DTXLNs are valuable as an oral drug delivery system to enhance the absorption of docetaxel.

\section{Acknowledgments}

This work was supported by the National Basic Research Program of China (973 Program, 2009CB930300) and the Nano-specific Project of Shanghai Science and Technology Commission (1052nm05100; 11nm0506700).

\section{Disclosure}

The authors report no conflicts of interest in this work.

\section{References}

1. Yan YD, Kim DH, Sung JH, Yong CS, Choi HG. Enhanced oral bioavailability of docetaxel in rats by four consecutive days of pretreatment with curcumin. Int J Pharm. 2010;399(1-2):116-120.

2. Straubinger RM, Balasubramanian SV. Preparation and characterization of taxane-containing lipsomes. Methods Enzymol. 2005;391:97-117.

3. ten Tije AJ, Verweij J, Loos WJ, Sparreboom A. Pharmacological effects of formulation vehicles: implications for cancer chemotherapy. Clin Pharmacokinet. 2003;42(7):665-685.

4. Yin YM, Cui FD, Mu CF, et al. Docetaxel microemulsion for enhanced oral bioavailability: preparation and in vitro and in vivo evaluation. $J$ Control Release. 2009;140(2):86-94.

5. Lee E, Kim H, Lee IH, Jon S. In vivo antitumor effects of chitosanconjugated docetaxel after oral administration. J Control Release. 2009; 140(2):79-85.

6. Moes JJ, Koolen SL, Huitema AD, Schellens JH, Beijnen JH, Nuijen B. Pharmaceutical development and preliminary clinical testing of an oral solid dispersion formulation of docetaxel (ModraDoc001). Int J Pharm. 2011;420(2):244-250.

7. Yin Y, Chen D, Qiao M, Lu Z, Hu H. Preparation and evaluation of lectin-conjugated PLGA nanoparticles for oral delivery of thymopentin. $J$ Control Release. 2006;116(3):337-345.

8. Malam Y, Loizidou M, Seifalian AM. Liposomes and nanoparticles: nanosized vehicles for drug delivery in cancer. Trends Pharmacol Sci. 2009;30(11):592-599.
9. Maincent P, Devissaguet JP, LeVerge R, Sado PA, Couvreur P. Preparation and in vivo studies of a new drug delivery system. Nanoparticles of alkylcyanoacrylate. Appl Biochem Biotechnol. 1984;10:263-265.

10. Maincent P, LeVerge R, Sado P, Couvreur P, Devissaguet JP. Disposition kinetics and oral bioavailability of vincamine-loaded polyalkylcyanoacrylate nanoparticles. J Pharm Sci. 1986;75(10): 955-958.

11. Sakuma S, Suzuki N, Kikuchi H, et al. Oral peptide delivery using nanoparticles composed of novel graft copolymers having hydrophobic backbone and hydrophilic branches. Int J Pharm. 1997;149(1): 93-106.

12. Yanasarn N, Sloat BR, Cui Z. Nanoparticles engineered from lecithinin-water emulsions as a potential delivery system for docetaxel. Int $J$ Pharm. 2009;379(1):174-180.

13. De Muynck C, Cuvelier C, Remon JP. Evaluation of rectal mucosal irritation in rabbits after sub-chronic administration of lecithin-containing suppositories. J Pharm Pharmacol. 1994;46(1):78-79.

14. Florence AT. Nanoparticle uptake by the oral route: fulfilling its potential? Drug Discov Today Technol. 2005;2(1):75-81.

15. Win KY, Feng SS. Effects of particle size and surface coating on cellular uptake of polymeric nanoparticles for oral delivery of anticancer drugs. Biomaterials. 2005;26(15):2713-2722.

16. Musumeci T, Ventura CA, Giannone I, et al. PLA/PLGA nanoparticles for sustained release of docetaxel. Int J Pharm. 2006;325(1-2):172-179.

17. Pandita D, Ahuja A, Lather V, et al. Development of lipid-based nanoparticles for enhancing the oral bioavailability of paclitaxel. AAPS Pharm Sci Tech. 2011;12(2):712-722.

18. Sun H, Chow EC, Liu S, Du Y, Pang KS. The Caco-2 cell monolayer: usefulness and limitations. Expert Opin Drug Metab Toxicol. 2008;4(4): 395-411.

19. Ben Reguiga M, Bonhomme-Faivre L, Farinotti R. Bioavailability and tissular distribution of docetaxel, a P-glycoprotein substrate, are modified by interferon-alpha in rats. J Pharm Pharmacol. 2007;59(3): 401-408.

20. Li H, Zhao X, Ma Y, Zhai G, Li L, Lou H. Enhancement of gastrointestinal absorption of quercetin by solid lipid nanoparticles. J Control Release. 2009;133(3):238-244.

21. Ma Y, Zhao X, Li J, Shen Q. The comparison of different daidzeinPLGA nanoparticles in increasing its oral bioavailability. Int $J$ Nanomedicine. 2012;7:559-570.

22. Cho CW. Formulation strategy to overcome multi-drug resistance (MDR). Arch Pharm Res. 2011;34(4):511-513.

23. Dong X, Mattingly CA, Tseng MT, et al. Doxorubicin and paclitaxelloaded lipid-based nanoparticles overcome multidrug resistance by inhibiting P-glycoprotein and depleting ATP. Cancer Res. 2009;69(9): 3918-3926.

24. Regev R, Katzir H, Yeheskely-Hayon D, Eytan GD. Modulation of P-glycoprotein-mediated multidrug resistance by acceleration of passive drug permeation across the plasma membrane. FEBS J. 2007;274(23): 6204-6214.

25. Guan M, Zhu QL, Liu Y, et al. Uptake and transport of a novel anticancer drug-delivery system: lactosyl-norcantharidin-associated N-trimethyl chitosan nanoparticles across intestinal Caco-2 cell monolayers. Int $J$ Nanomedicine. 2012;7:1921-1930.

26. Conner SD, Schmid SL. Regulated portals of entry into the cell. Nature. 2003;422(6927):37-44.

27. des Rieux A, Fievez V, Garinot M, Schneider YJ, Preat V. Nanoparticles as potential oral delivery systems of proteins and vaccines: a mechanistic approach. J Control Release. 2006;116(1):1-27.

28. Yuan H, Chen J, Du YZ, Hu FQ, Zeng S, Zhao HL. Studies on oral absorption of stearic acid SLN by a novel fluorometric method. Colloids Surf B Biointerfaces. 2007;58(2):157-164.

29. Duchene D, Ponchel G. Bioadhesion of solid oral dosage forms, why and how? Eur J Pharm Biopharm. 1997;44(1):15-23.

30. Venkatesan N, Uchino K, Amagase K, Ito Y, Shibata N, Takada K. Gastro-intestinal patch system for the delivery of erythropoietin. J Control Release. 2006;111(1-2):19-26. 
International Journal of Nanomedicine

Dovepress

\section{Publish your work in this journal}

The International Journal of Nanomedicine is an international, peerreviewed journal focusing on the application of nanotechnology in diagnostics, therapeutics, and drug delivery systems throughou the biomedical field. This journal is indexed on PubMed Central, MedLine, CAS, SciSearch ${ }^{\circledR}$, Current Contents ${ }^{\circledR} /$ Clinical Medicine,
Journal Citation Reports/Science Edition, EMBase, Scopus and the Elsevier Bibliographic databases. The manuscript management system is completely online and includes a very quick and fair peer-review system, which is all easy to use. Visit http://www.dovepress.com/ testimonials.php to read real quotes from published authors.

Submit your manuscript here: http://www.dovepress.com/international-journal-of-nanomedicine-journal 